\title{
DEPTH OF CLOSURE DETERMINATION IN THE VICINITY OF COASTAL STRUCTURE
}

\author{
Widyaningtias $^{1}$, Hitoshi Tanaka ${ }^{2}$ and Susumu Kanayama ${ }^{3}$
}

\begin{abstract}
This study is conducted to analyze the effect of coastal structure to depth of closure variation. Analysis on time series bathymetry data has been applied to determine location of depth of closure. The deviation of bathymetry profile changing is also considered. Furthermore, longshore variation of depth of closure is proposed. The hydrodynamic conditions are simulated using Boussinesq model derived by Peregrine (1967). This model is applied considering its applicability to observe non-linear and dispersion phenomenon while wave propagates to the shoreline. The simulation is carried out under regular wave assumption with $20 \%$ wave height in deep area is applied as representative wave. The simulation results are obtained in term of surface water level, bottom velocity in $\mathrm{x}$ and $\mathrm{y}$ direction and current velocity. The result is utilized to calculate maximum bottom velocity just outside boundary layer. To observe sediment movement along the coast, maximum shear stress is calculated under wave-current combined motion. Dimensionless Shields parameter is also assessed. The simulation results are depicted in spatial map. Furthermore, the effect of coastal structure to depth of closure variation is confirmed using hydrodynamic conditions.
\end{abstract}

Keywords: depth of closure, coastal structure, hydrodynamic conditions

\section{INTRODUCTION}

\section{Background}

Depth of closure $\left(h_{c}\right)$ concept was firstly introduced by Hallermeier (1981), as the boundary between shoal zone and littoral zone. These two zones were defined in particularly on wave-dominated sand beaches: the littoral zone which extends to the seaward limit of intense bed activity caused by extreme near-breaking waves and breaker-related currents; and the shoal zone as the area where wave have neither strong nor negligible effect on the sand bed. Seaward of this depth, although the waves can move sediment, the net transport does not result in significant changes in mean water depth. Moreover, although some bathymetric movement occurs deeper than $h_{c}$, however the shoreline position is not directly controlled.

Many definitions are applied in order to understand $h_{c}$ concept. Another terminology of $h_{c}$ as the closeout depth (Birkemeier, 1985) is considered to separate the active zone of nearshore sediment transport from a deeper zone of negligible sediment deposition and/or erosion under a certain temporal scale (Kraus et al., 1999). Recently, it is well established that $h_{c}$ becomes deeper with increasing duration of observation (Hinton and Nicholls, 1998; Nicholls et al., 1998a; Francois et al., 2004; Capobianco et al., 1997). This was proved by a study in Holland Coast (Hinton and Nicholls, 1998). They obtained $8 \mathrm{~m}$ depth of $h_{c}$ using five years bathymetry data. Meanwhile using 20 years bathymetry data it was estimated $h_{c}$ in $9 \mathrm{~m}$ depth. Furthermore, on the developing theory and its application, it is observed that longshore variation of $h_{c}$ exists (List et al., 1997, Gracia et al., 1995; 1998; Hinton and Nicholls, 1998; Nicholls et al., 1998b; Rozynski et al., 1999; Wang and Davis, 1999).

Several methods can be used to determine $h_{c}$. However, the constant value of $h_{c}$ is obtained rather than the longshore variation, as studies conducted by Nomura et al., (1986) and Uda (1997). They used bathymetry data from several coasts in Japan and obtained $h_{c}$ as constant value. A research concern on $h_{c}$ application has been done in Duck, USA by Nicholls et al. (1998b). They used 12 years bathymetry data and applied their result to evaluate accretion and erosion phenomenon in the coastal. The concept of $h_{c}$ explained previously was applied to analyze shoreline change in Sendai Coast by Pradjoko et al. (2011). To simplify computation, the constant value of $h_{c}$ prefers to use rather than longshore variation of $h_{c}$.

Moreover, it is well known that one line model is one of simple approach to analyze shore line change (Shibutani et al., 2007; Zacharioudaki and Reeve, 2009) according its usage of constant $h_{c}$. However, if we consider the actual condition, it is unattainable constant $h_{c}$ exist in nature. The more accurate result will be assessed if we consider the longshore variation of $h_{c}$ as well as observing more accurate nature phenomenon. For example, due to the existence of coastal structure, accumulating of

\footnotetext{
${ }^{1}$ Graduate student, Department of Civil Engineering, Tohoku University, 6-6-06 Aoba, Sendai, Miyagi, 980-8579, Japan

2 Professor, Department of Civil Engineering, Tohoku University, 6-6-06 Aoba, Sendai, Miyagi, 980-8579, Japan

${ }^{3}$ Senior Research Engineer, Penta-Ocean Construction Co., Ltd, 1534-1, Yonkucho, Nasushiobara-shi, Tochigi 3292746, Japan
} 
wave energy will give different response to bottom topography and hydrodynamic conditions, especially in the area near structure. Using constant value of $h_{c}$, the complexity of this phenomenon might not be explained accurately.

One study that was considering the longshore variation of $h_{c}$ was proposed by Francois et al. (2004). He used four years bathymetry data (medium-scale) in Gulf, Lion, France, a micro-tidal wavedominated coast. Several cross sections were taken to estimate longshore variation of $h_{c}$. Furthermore, the result was confirmed analytically. In a fact that there is still lack of study in term of longshore variation of $h_{c}$, this topic becomes more interesting and challenging in coastal field, especially to study dealing with beach nourishment design, planning of beach profile surveys, installation of coastal structures, sediment budget analysis (Kraus et al., 1999) and shoreline change analysis (Hanson and Kraus, 2011).

In this paper, the longshore variation will be produced using bathymetry data. The influence of coastal structure will be analyzed. Determination of longshore variation of $h_{c}$ will be confirmed using dimensionless Shields parameter. This present study has main purpose, which is to clarify the effect of coastal structure on depth of closure variation and hydrodynamic conditions. The specific objectives cover:

- To determine the depth of closure location and propose its longshore variation.

- To simulate the hydrodynamic conditions and confirm the result using longshore variation of depth of closure.

\section{Study area}

To achieve the objectives, two study areas will be brought in this research. The first study area is Sendai Port that is located in the north part of Sendai Bay Coast, Miyagi Prefecture, Japan. Breakwater constructed during 1968 to 1973 is situated in that area as shown in Fig. 1. The length of breakwater is approximately $2 \mathrm{~km}$. The existence of breakwater in this area is possible to generate reflected wave and arise longshore sediment transport. The breakwater was continuously installed from June 1968 to March 1973. Due to the severe erosion; the wing was constructed during 1977 to 1979. Bathymetry data from 1967 to 1998 was obtained from field observation conducted by government. The data sheets consist of old map (1967 to 1983) and digital data (1986 to 1998).

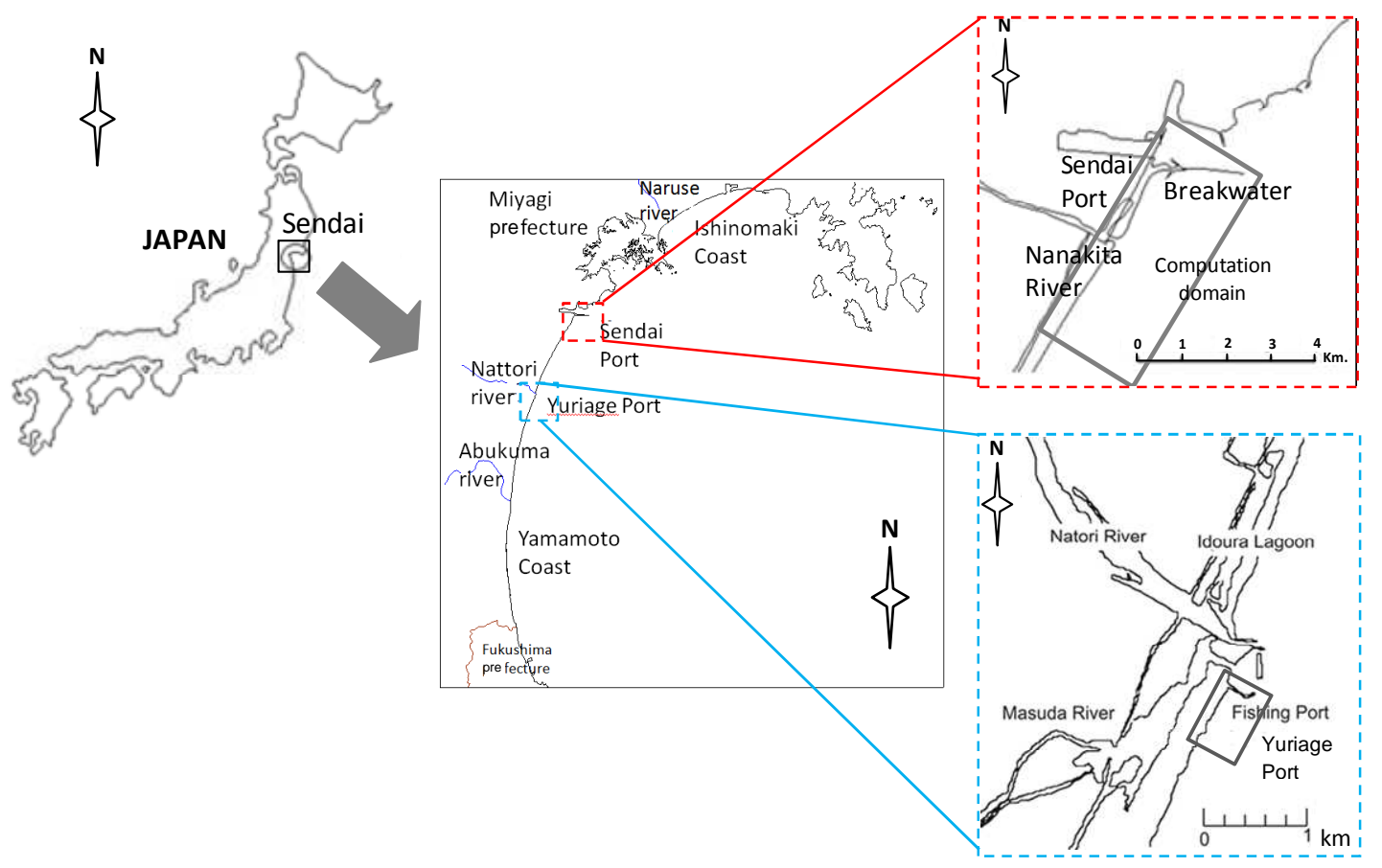

Figure 1. Study area, Sendai Port and Yuriage Port 
The second study area is Yuriage Port. It is located in the downstream of Nattori River, in the southern part of Sendai Bay Coast that is also shown in Fig. 1. This coastal is situated with approximately $700 \mathrm{~m}$ breakwater that was installed after 1970's. Two jetties were also constructed in that location. In the 1990's the fishing port was installed. The new entrance of ship navigation was constructed after that. The new port is composed of northern and southern jetties and a perpendicular to those two jetties. For this study area, bathymetry data was obtained from 1983 to 1997 . Wave data was obtained from 1991 to 2003. In Sendai Bay Coast, wave is predominantly coming from ESE and SE direction (Tanaka and Takahashi, 1995). For further analysis, considering the similar condition of wave propagation along the bay, it will be utilized same wave data for Sendai Port and Yuriage Port.

\section{METODOLOGY}

\section{Wave modeling}

Research on predicting the wave transformation from deep to shallow water influenced by different response of hydrodynamic conditions have been conducted by many researchers. Combination of shoaling, refraction, diffraction, reflection and wave breaking will affect the modification of waveform at the time wave propagates to the shoreline. The difference of coastal morphology can also cause difference response on wave propagation.

One of model that can assess this phenomenon is Boussinesq model (1872). The governing equation was derived under the assumption that the magnitude of the vertical velocity increases polynomially from the bottom to the free surface, which inevitably leads to some form of depth limitation in the accuracy of the embedded dispersive and nonlinear properties. This earlier model was also derived for horizontal bottom only.

This model is successfully utilized to observe wave phenomenon in nearshore zone. Shoaling, refraction, diffraction and reflection can be observed by considering nonlinearity term (Abbott et al., 1973, 1978, 1984; Abbott, 1974; Kennedy et al., 2000). However, earlier model has some limitations. Although an extra term from vertical acceleration on the water pressure had already been included, but it was still limited for small amplitude wave (Peregrine, 1967). Dispersion characteristic is still poorly simulated, especially for wave approaches the shoreline with more than $20 \%$ of the wave length (Beji and Battjes, 1994).

The model that applied in this analysis was modified based on long wave theory for varying depth and developed the depth-integrated velocity as the dependent variable (Peregrine, 1967). This improving model is referred as standard Boussinesq equation, which are able to describe the nonlinear transformation of irregular and multidirectional waves in shallow water. The wave reflection criterion was also included in the solution.

The standard Boussinesq equation has major limitation that by using depth-averaged model the frequency dispersion of wave propagation in intermediate depths and the weakly nonlinear assumption is poorly described, thus it is only applicable to relatively shallow water depth. However to keep errors in the phase velocity less that $5 \%$, the water depth has to be less than about one fifth of the equivalent deep-water wavelength (McCowan, 1987).

The governing equation of fluid motion is taken based on Euler's equation as in equations below:

$$
\frac{\partial \mathbf{u}}{\partial t}+(\mathbf{u} \cdot \nabla) \mathbf{u}+w\left(\frac{\partial \mathbf{u}}{\partial z}\right)+\nabla \mathrm{p}=0
$$

and

$$
\frac{\partial w}{\partial t}+(\mathbf{u} \cdot \nabla) w+w\left(\frac{\partial w}{\partial z}\right)+\left(\frac{\partial p}{\partial z}\right)+1=0
$$

The continuity equation is expressed below:

$$
\nabla \mathbf{u}+\left(\frac{\partial w}{\partial z}\right)=0
$$

with $\mathbf{u}=(u, v)$ is the two dimensional depth-averaged velocity in $x$ and $y$ direction and $w$ is velocity in $z$ direction. The subscript $\partial t$ is partial differentiation that respect to time and $p$ is pressure. $\nabla$ is vector operator for two-dimensional problem ( $\partial / \partial \mathrm{x}, \partial / \partial \mathrm{y})$, with $x, y$ and $z$ are the coordinate system.

The boundary conditions that were used in the derivation are: 


$$
p=0 \quad \text { at } z=\eta(x, y, t)
$$

And

$$
(\mathbf{u} \cdot \nabla) h+w=0 \quad \text { at } z=-h(x, y)
$$

in which $h$ is water depth. Irrotational motion is assumed so that

$$
\frac{\partial u}{\partial y}=\frac{\partial v}{\partial x}
$$

And

$$
\frac{\partial \mathbf{u}}{\partial z}=\nabla w
$$

The long wave theory is basically developed which respect to these parameters; non-linear effect which is expressed to ratio of wave amplitude to the depth $(\varepsilon)$ and dispersive effect which is represented to ratio of depth to typical wavelength $(\mu)$. The long wave is noted satisfying the condition $\mu \leq 1$. Finite amplitude theory satisfies $\varepsilon=O(1)$. For the development, it was assumed that Boussinesq equation satisfies the same order of $\varepsilon$ and $\mu^{2}$.

The governing equations are expressed as conservation of mass and momentum:

$$
\begin{gathered}
\frac{\partial \eta}{\partial t}+\nabla \cdot[(h+\eta) \mathbf{u}]=0 \\
\frac{\partial \mathbf{u}}{\partial t}+(\mathbf{u} \cdot \nabla) \mathbf{u}+g \nabla \eta \\
=\frac{1}{2} h \frac{\partial}{\partial t} \nabla[\nabla \cdot h \mathbf{u}] \\
-\frac{1}{6} h^{2} \frac{\partial}{\partial t} \nabla(\nabla \cdot \mathbf{u})
\end{gathered}
$$

where $\eta$ is the surface water elevation and $g$ is gravity acceleration.

Finite different approximation is applied for the discretization. Explicit formulation is used for the conservation of mass to obtain first estimation of the surface water level at the new time level $(t+\Delta t)$. Its result furthermore is used in implicit discretization for the momentum equation to compute the velocity at the new time level $(t+\Delta t)$.

The Boussinesq-type equation, which include the weak non-linearity and frequency dispersion provide an accurate description of wave transformation processes outside the surf zone. However, the Boussinesq equation does not automatically lead to wave breaking in shallow water or to predict the wave in the surf zone. Then a natural step forward is an extension of the Boussinesq equations to cover the surf zone. The extension will require introduction of wave breaking criterion and the introduction of energy dissipation. From the physical point of view, wave breaking is a process, which involves strong turbulence and momentum mixing in particular at the front face of the wave.

One advantage of extending Boussinesq-type model to the surf zone is the ability to implicitly model interactions between hydrodynamic processes occurring at the different time scale. Waveinduced currents and mean sea water level fluctuations are implicitly included in the wave propagation model and are derived from a time-average of the predicted velocities and surface wave elevation, respectively, without having to explicitly calculate radiation stresses and separately solve a timeaveraged hydrodynamic model.

There have been attempts to introduce wave breaking into Boussinesq models in order to model breaking phenomena such as wave height decay, wave-induced set up, and run up. The model essentially incorporates a dissipative term due to turbulence stresses or the presence of a surface roller into the momentum equation.

Simulation of wave breaking in Boussinesq models has been approached with a number of techniques, ranging from fairly additions of eddy viscosity formulations up to reasonably detailed calculations of the generation and transport of vorticity or turbulent kinetic energy under the breaking wave crest (Zelt, 1991; Karambas and Koutitas, 1992; Schäffer et al., 1993; Kabiling and Sato, 1994; 
Nwogu, 1996; Svendsen, 1996; Kennedy, 2000). Regardless of the formulation, each of the approaches can be thought of as a means for adding the breaking wave force term to momentum equation.

Referring the analysis conducted by Kabiling and Sato (1994), the energy dissipation due to wave breaking inside the surf zone was modeled with a momentum mixing term $\left(M_{D}\right)$ using eddy viscosity; $v_{e}$. Modeling of the momentum exchange due to turbulence will possibly lead to the following formulation of $M_{D}$ in term of $v_{e}$ :

$$
\begin{gathered}
M_{D}=\left(v_{e}+v_{L}\right) \nabla(\nabla \cdot D \mathbf{u}) \\
v_{e}=\frac{\alpha_{D} s g \bar{D}}{\omega^{2}} \sqrt{\left(\frac{g}{\bar{D}}\right)\left(\frac{\hat{Q}-Q_{r}}{Q_{S}-Q_{r}}\right)}
\end{gathered}
$$

where $v_{L}$ is the additional eddy viscosity to avoid such large velocities, $\alpha_{D}$ is a coefficient which is 2.5 inside the surf zone and zero elsewhere, $s$ is the bottom slope, $\bar{D}$ is mean water depth $(D=h+\eta), \omega$ is angular frequency, $\hat{Q}$ is the amplitude of $Q$, where $Q(=\mathbf{u} D)$ and $Q_{r}$ and $Q_{s}$ are determined from the following equation:

$$
\begin{gathered}
Q_{S}=0.4(0.57+5.3 s) \sqrt{g \bar{D}^{3}} \\
Q_{r}=0.135 \sqrt{g \bar{D}^{3}}
\end{gathered}
$$

The $v_{L}$ was found to be similar to that proposed by Longuet-Higgins (1970) as:

$$
v_{L}=N l s \sqrt{g \bar{D}^{3}}
$$

where $N$ is equal to 0.016 and $l$ is horizontal distance from the shoreline.

In this study waves condition will be simulated using wave modeling. Input bathymetry will utilize 1998 and 1997 bathymetry data for Sendai Port and Yuriage Port, respectively. 20\% wave height in deep area $\left(H_{0}\right)$ is applied as representative wave height and assumed as regular wave, with $H=1.15 \mathrm{~m}$ and correspond wave period, $T=7.55 \mathrm{sec}$. Grid system is carried out using $\Delta x=\Delta y=5 \mathrm{~m}$ and $\Delta t=0.1 \mathrm{sec}$ for both study area.

\section{Shields parameter approach}

In term to the forces acting on a sediment particle, dimensionless Shields parameter is one approach that is commonly used. The basic concept of Shields parameter itself starts from the assumption of the movement of sediment in a steady flow. Dimensionless Shields parameter $\left(\tau_{0}^{*}\right)$ is calculated using expression as follows:

$$
\tau_{0}^{*}=\frac{\tau_{0 \max }}{\left(\rho_{s}-\rho\right) g d_{50}}
$$

where $\tau_{\text {max }}$ is maximum bottom shear stress and $d_{50}$ is mean particle diameter (for this study it will use $d_{50}=0.026 \mathrm{~cm}$ ). It was observed by Dean and Dalrymple (2004) that if $\tau_{0}^{*}$ exceeds the value of 0.1 , then it is almost certain that the bed is moving. For value of $\tau_{0}^{*}$ exceeding the incipient motion criterion, different bed forms may result.

In this study bottom shear stress is calculated using the maximum wave-induced horizontal velocity near the bed $\left(u_{b \max }\right)$ component. This parameter is obtained from wave modeling. Furthermore, maximum bottom shear stress $\left(\tau_{\sigma_{\max }}\right)$ component is calculated using following expression:

$$
\tau_{0 \max }=\frac{1}{2} \rho f_{c w} u_{b \max }^{2}
$$

where $\rho$ is density of water, $f_{c w}$ is friction factor under wave-current combined motion. 
Considering the flow regime, $f_{c w}$ for rough turbulent regime derived by Tanaka and Thu (1994) will be applied. Although it did not include wave reflection criterion on its derivation, however, it is very convenient to use for practical application considering it does not need complex approximation to obtain the solution since it was derived as explicit form. The variable of $f_{c w}$ using in this computation is introduced as:

$$
f_{c w}=f_{c}+2 \sqrt{f_{c} \beta f_{w}} \cos \phi^{\prime}+\beta f_{w}
$$

where

$$
\begin{gathered}
f_{c}=\frac{2 \kappa^{2}}{\left\{\ln \left(z_{h} / z_{0}\right)-1\right\}^{2}}\left(\frac{\bar{u}_{c}}{u_{b \max }}\right)^{2} \\
f_{w}=\exp \left\{-7.53+8.07\left(\frac{u_{b \max }}{\omega z_{0}}\right)^{-0.100}\right\} \\
\beta=\frac{1}{1+0.769 \alpha^{0.830}}\left\{1+0.863 \alpha \exp (-1.43 \alpha)\left(\frac{2 \phi^{\prime}}{\pi}\right)^{2}\right\}
\end{gathered}
$$

with $\alpha$ is calculated as follows:

$$
\alpha=\frac{1}{\ln \left(z_{h} / z_{0}\right)-1} \frac{\bar{u}_{c}}{u_{b \max }}
$$

where $f_{c}$ is steady current friction factor, $f_{w}$ is wave friction factor, $\kappa$ is von Karman constant $(=0.4)$, and $\bar{u}_{c}$ is component of the depth-average mean velocity of the steady current. $z_{h}$ is the water depth, $z_{0}$ is the roughness length $\left(z_{0}=k_{s} / 30, k_{s}\right.$ : Nikuradse's equivalent roughness). $k_{s}$ here is expressed in term of median grain size diameter and

$$
\phi^{\prime}=\cos ^{-1}(|\cos \phi|) \quad\left(0 \leq \phi^{\prime} \leq \pi / 2,0 \leq \phi \leq 2 \pi\right)
$$

\section{DEPTH OF CLOSURE DETERMINATION USING BATHYMETRY DATA}

\section{Sendai Port}

Considering the accuracy of field data, $h_{c}$ along Sendai Coast is predicted using 1988 to 1998 bathymetry data series. The prediction of $h_{c}$ here is considered to satisfy the standard deviation $(\sigma)$ for bathymetry change as $0.1 \mathrm{~m}$. A study conducted by Francois et al. (2004) determined the value of $\sigma$ falls to $0.3 \mathrm{~m}$. Meanwhile Hinton and Nicholls (1998) applied value of $\sigma$ about $0.25 \mathrm{~m}$. It is mentioned in their result that $\sigma$ taken in their analysis as more closely connected to the accuracy of the field measurement. Although for present study any data on the operational survey accuracy was not obtained as in research conducted by Nicholls et al. (1998a, 1998b), however the smaller value of $\sigma$ taken here represents that data series used in this study is tighter clustered around the mean value. To produce longshore variation of $h_{c}$, several cross sections are taken along the coast, with the domain area $3400 \mathrm{~m}$ and $1800 \mathrm{~m}$ as longshore and cross shore distance, respectively. The profiles in cross sections overlaid during 1988 to 1998 are given in Fig. 2 . Nine cross sections that were taken along $x=800 \mathrm{~m}$ to $x=2950 \mathrm{~m}$ produced $18 \mathrm{~m}$ as the maximum value of $h_{c}$ and $14.8 \mathrm{~m}$ as the minimum $h_{c}$.

Longshore variation of $h_{c}$ is proposed using each point of $h_{c}$ predicted. The profile of longshore variation of $h_{c}$ in Sendai Port is shown in Fig.3. The comparison approach has also been done using previous analysis obtained from Nomura et al. (1986) and Uda (1997). Nomura et al. (1986) utilized series of bathymetry data in Abukuma river from 1970 to 1974 and 1984 . He predicted the constant 
value of $h_{c}$ as value $7.5 \mathrm{~m}$. Meanwhile Uda (1997) used bathymetry data from Yamamoto Coast and obtained the result, $h_{c}=8 \mathrm{~m}$. The discrepancy in the area near structure is observed.

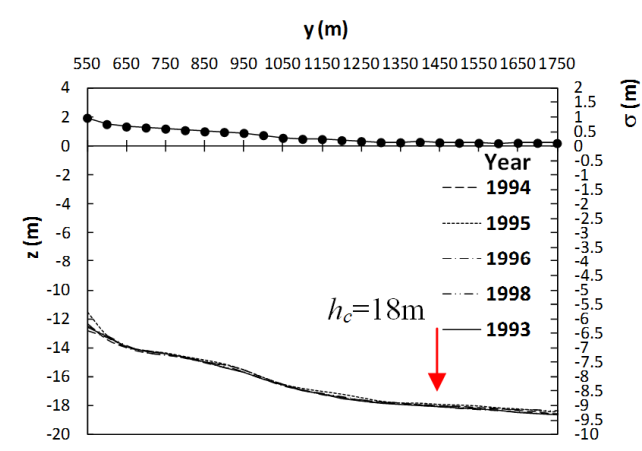

(a) $x=800 \mathrm{~m}$

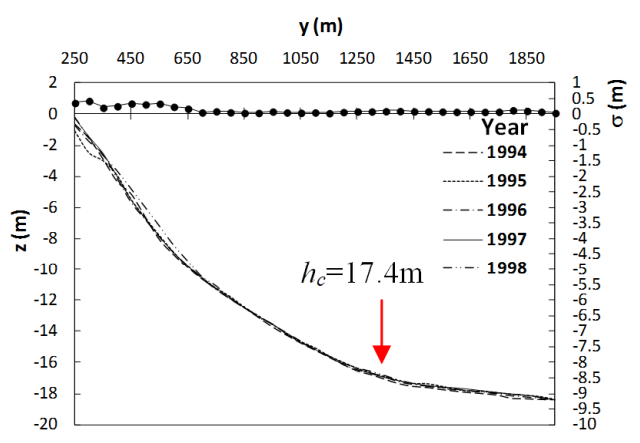

(c) $x=1100 \mathrm{~m}$

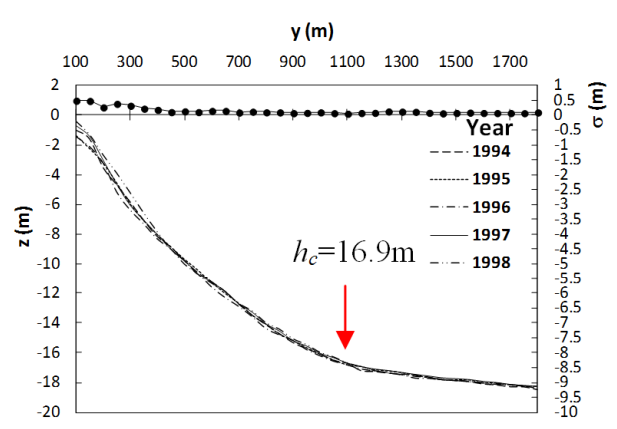

(e) $x=1850 \mathrm{~m}$

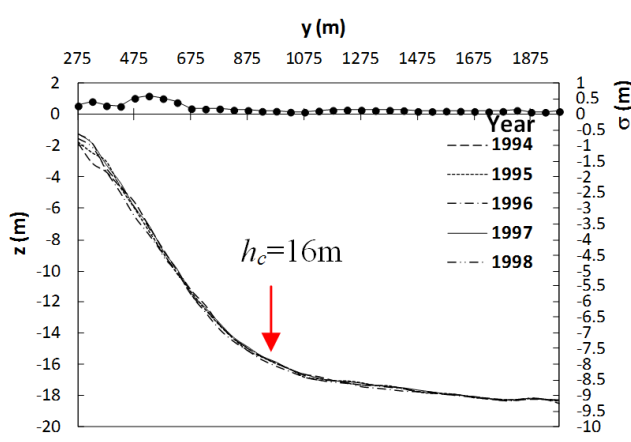

(g) $x=2250 \mathrm{~m}$

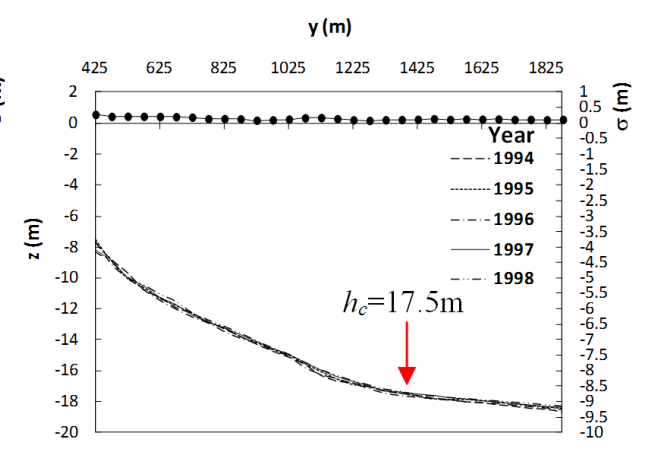

(b) $x=1100 \mathrm{~m}$

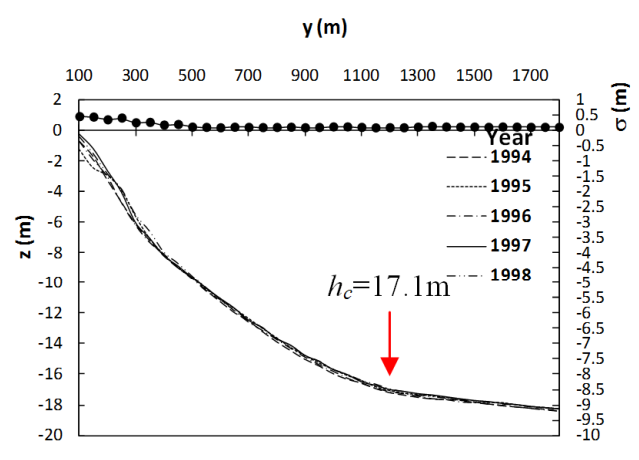

(d) $x=1600 \mathrm{~m}$

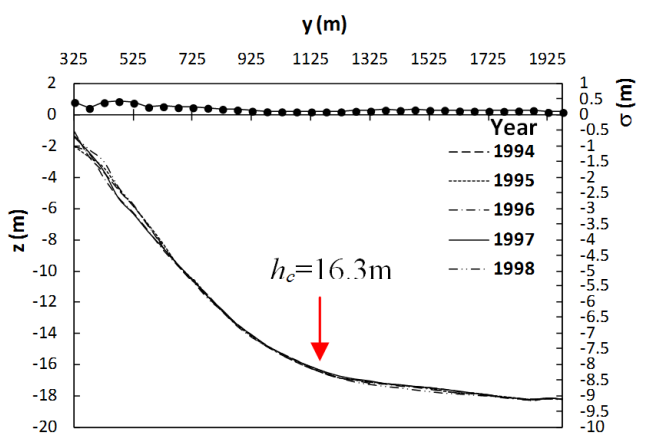

(f) $x=2100 \mathrm{~m}$

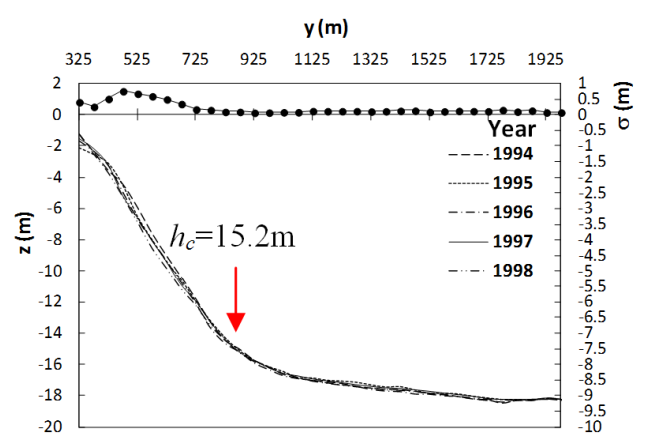

(h) $x=2650 \mathrm{~m}$

Figure 2. (see caption in the next page) 


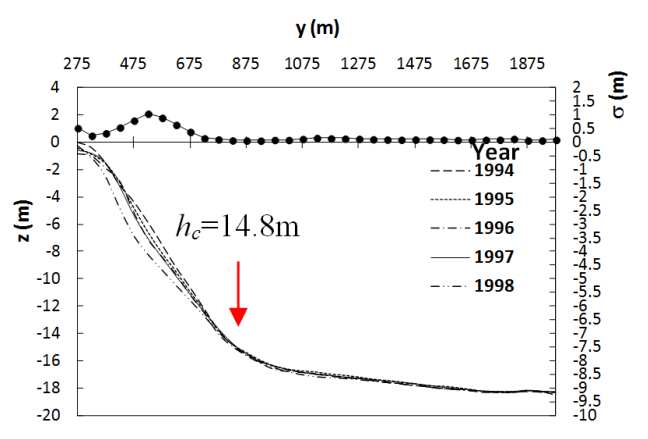

(i) $x=2950 \mathrm{~m}$

Figure 2. Cross sections of bathymetry data, Sendai Port

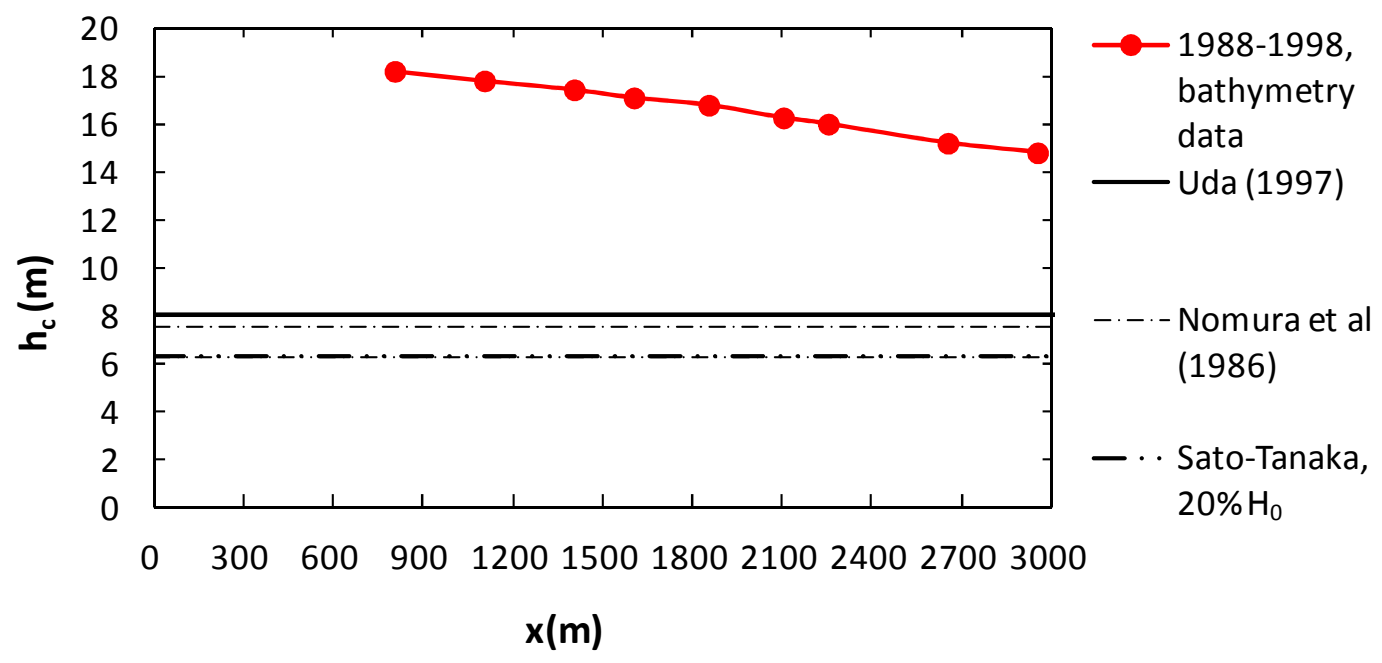

Figure 3. Longshore variation of $h_{c}$, Sendai Port

An approach using empirical method has been done by applying Sato and Tanaka formula (1962). $20 \% H_{0}$ and corresponds period, $H=1.15 \mathrm{~m}$ and $T=7.55 \mathrm{sec}$, are applied as representative wave height to calculate $h_{c}$ location. It is obtained constant value of $h_{c}=6.3 \mathrm{~m}$. Moreover, from Fig. 3 it can also be seen that deeper $h_{c}$ is observed in the area near structure and it become shallower as the distance increase.

\section{Yuriage Port}

Bathymetry data analysis for Yuriage Port is conducted using 1994 to 1997 data series without including 1996 data series. Bimonthly data were obtained in 1994 (October and November) and 1995 (November and December). Meanwhile for 1997 was only one data in March. The domain for bathymetry analysis covers $1200 \mathrm{~m}$ and $1000 \mathrm{~m}$ in longshore and cross shore distance, respectively.

The location of $h_{c}$ here will also be predicted by taking several cross sections along the coast and considering the value of $\sigma$ consistence with $\sigma$ applied in Sendai Port as order $0.1 \mathrm{~m}$. Predicted $h_{c}$ in each cross section can be seen in Fig. 4. Ten cross sections were taken from $x=500 m$ to $x=1175 m$. From this result, it is observed the maximum value of $h_{c}$ is predicted in $13.8 \mathrm{~m}$ and the minimum value of $h_{c}$ is fallen to $10.5 \mathrm{~m}$. Longshore variation of $h_{c}$ in Yuriage Port is proposed using estimated $h_{c}$ from each cross section. The profile is given in Fig. 5.

Comparison has been done using same value of constant $h_{c}$ as in Sendai Port. Furthermore, Sato and Tanaka formula has been applied as an empirical approach using same wave condition with Sendai Port. From Fig. 5 the discrepancy between $h_{c}$ obtained from previous analysis and present study is shown. Furthermore, deeper $h_{c}$ is also observed in the area near structure and as compare with area far from structure. 


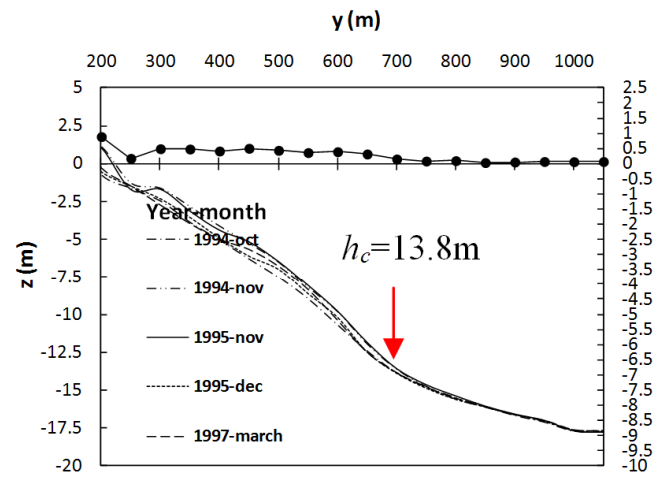

(a) $x=500 \mathrm{~m}$

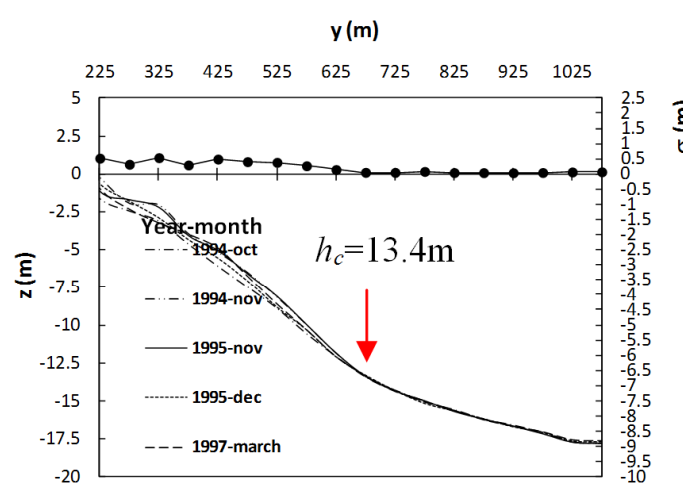

(c) $x=600 \mathrm{~m}$

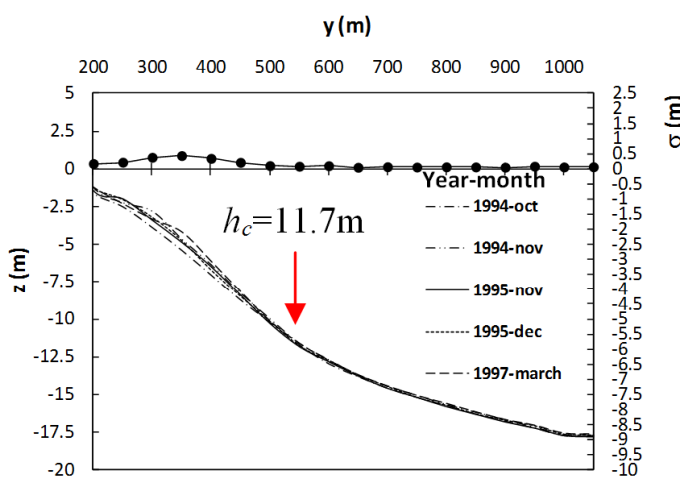

(e) $x=700 \mathrm{~m}$

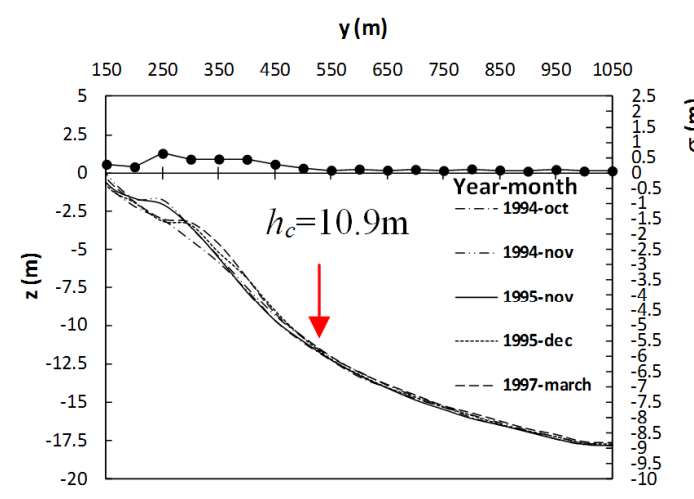

(g) $x=900 \mathrm{~m}$

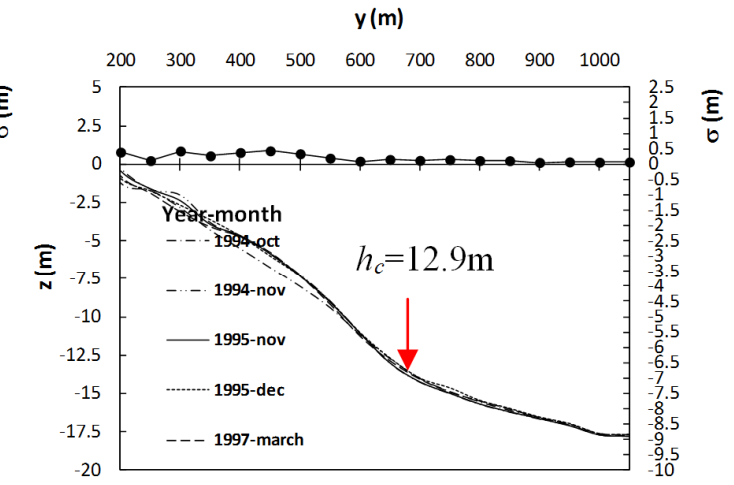

(b) $x=550 \mathrm{~m}$

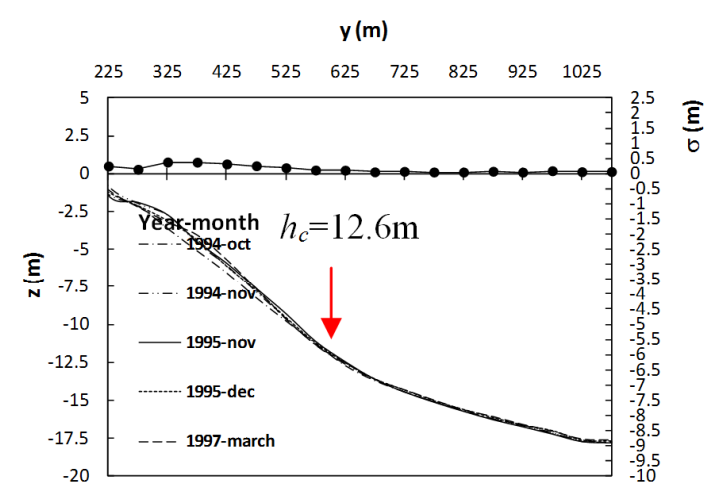

(d) $x=675 \mathrm{~m}$

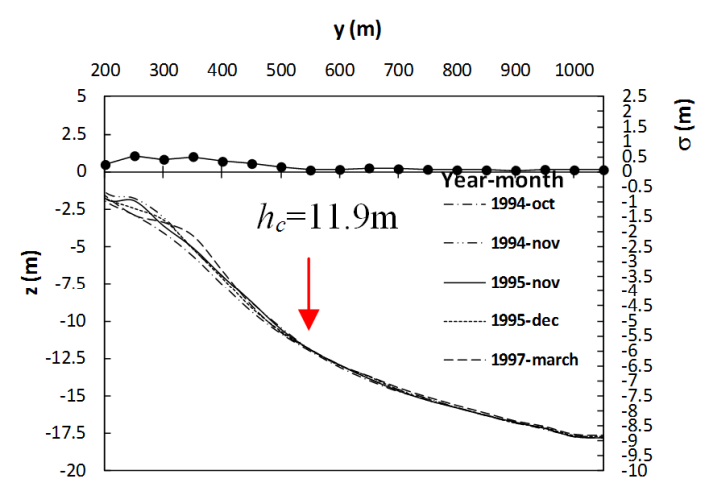

(f) $x=800 \mathrm{~m}$

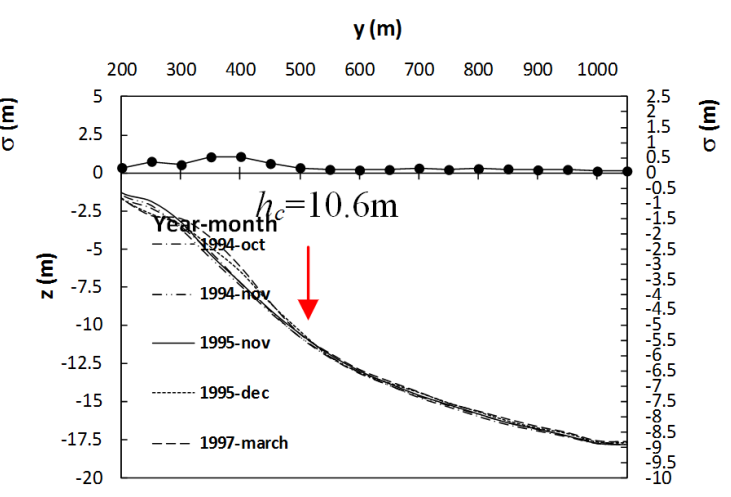

(h) $x=1000 \mathrm{~m}$

Figure 4. (see caption in the next page) 


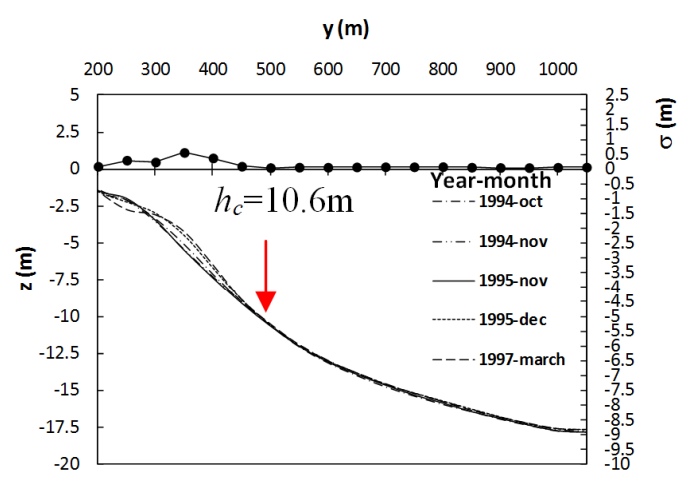

(i) $x=1075 \mathrm{~m}$

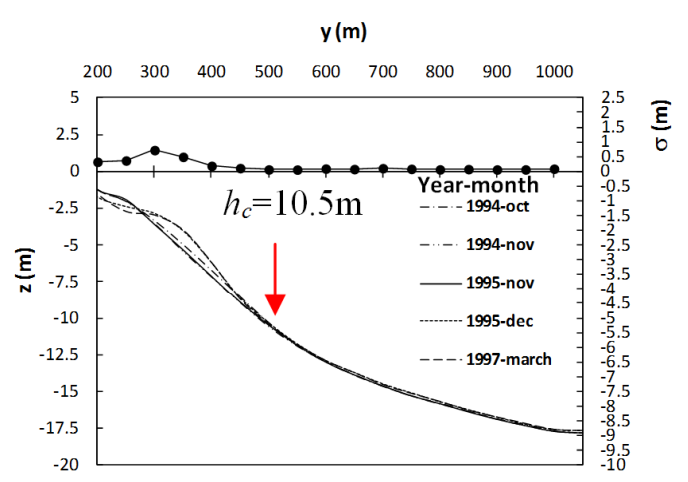

(j) $x=1175 \mathrm{~m}$

Figure 4. Cross sections of bathymetry data, Yuriage Port

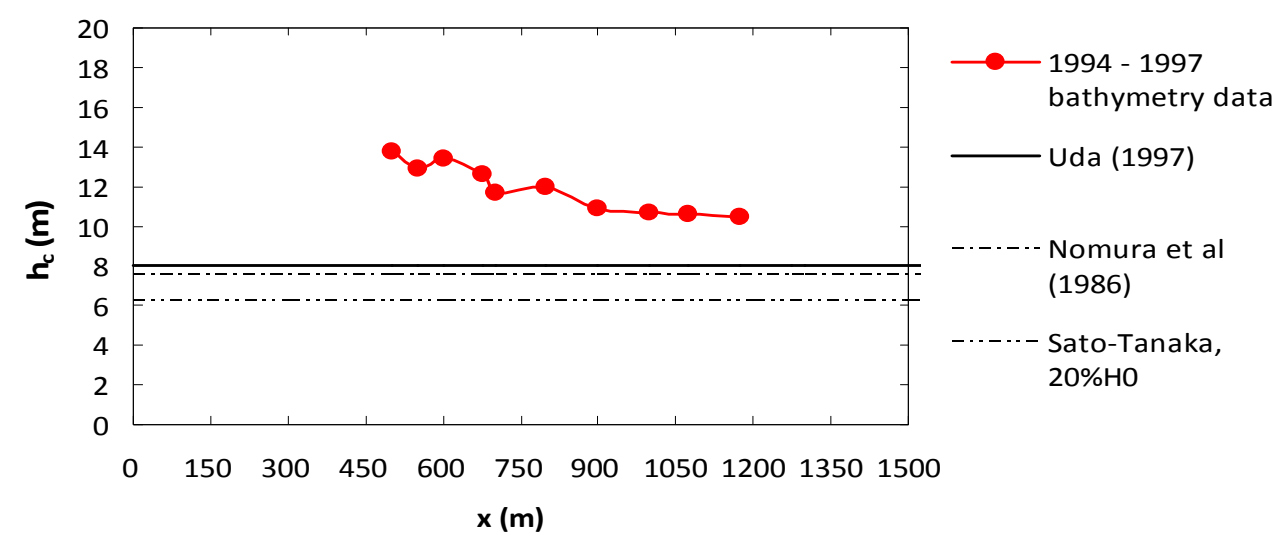

Figure 5. Longshore variation of $h_{c}$, Yuriage Port

\section{HYDRODYNAMIC SIMULATION}

\section{Shields parameter}

To estimate the effect of acting force to the weight acts downward, $\tau_{0^{*}}$ is assessed from $\tau_{\text {max }}$ obtained under wave-current combined motion. The result is depicted spatially as shown in Fig. 6. Due to the existence of breakwater and shoaling phenomenon in nearshore zone, different response on wave propagation produces higher wave height. Velocity is higher too. It causes the higher bottom shear stress. Furthermore, as its proportional relation with $\tau_{\text {omax }}$, higher $\tau_{0}^{*}$ is observed in the nearshore zone and also in the area near structure. The longshore variation of $h_{c}$ is overlaid on this spatial map. The location of $h_{c}$ is observed fell down in the $\tau_{0}^{*}=0.14$. To confirm the $\tau_{0}^{*}$ value in the location of $h_{c}$, several cross sections are taken in alongshore distance. The results are plotted in Fig. 7.

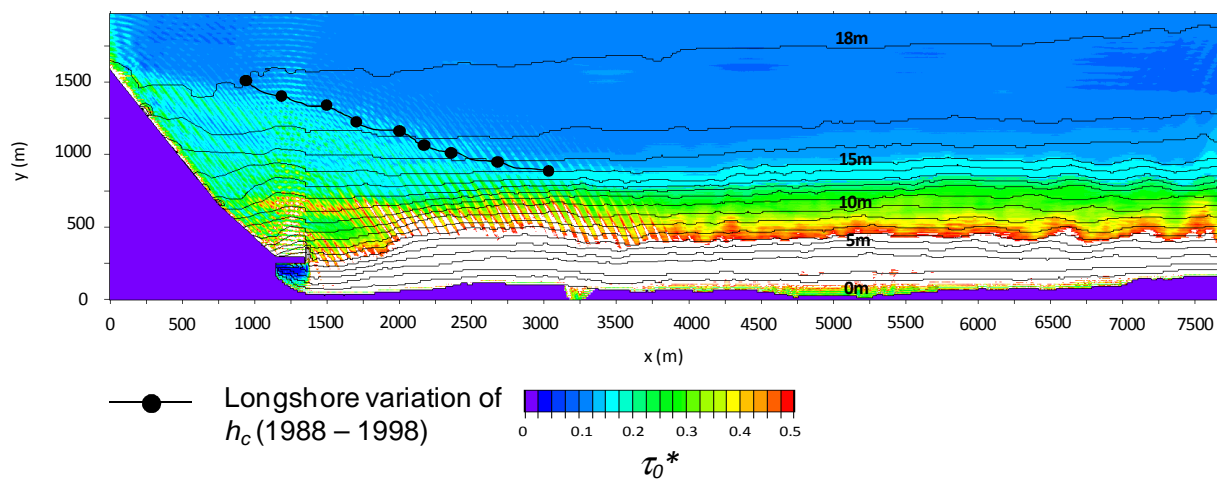

Figure 6. Shields parameter distribution, Sendai Port 


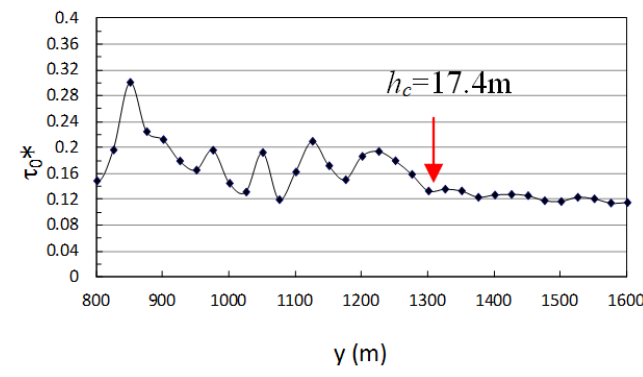

(a) $x=1400 \mathrm{~m}$

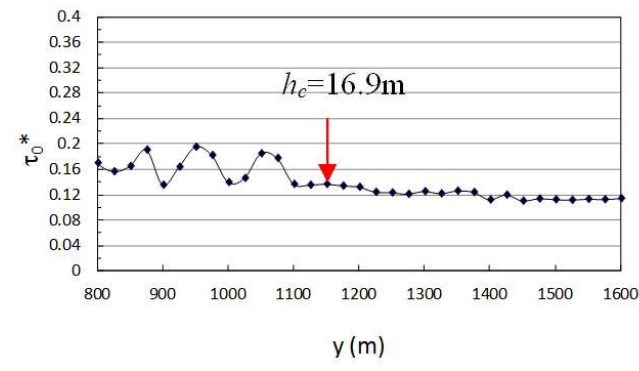

(c) $x=1850 \mathrm{~m}$

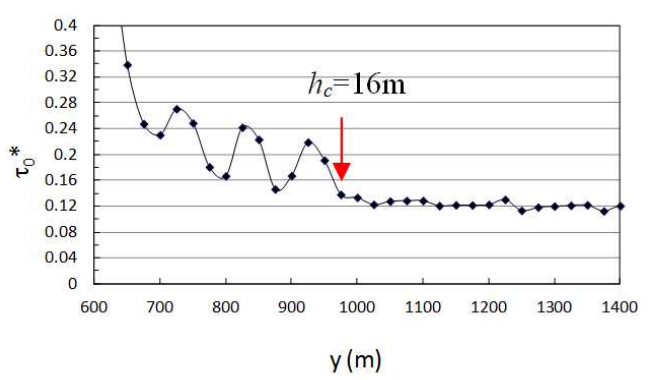

(e) $x=2250 \mathrm{~m}$

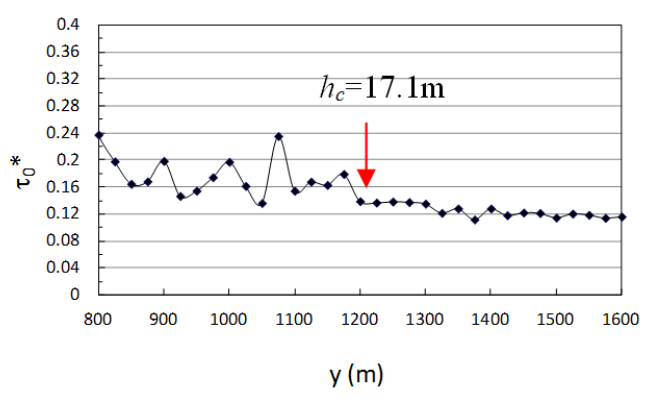

(b) $x=1600 \mathrm{~m}$

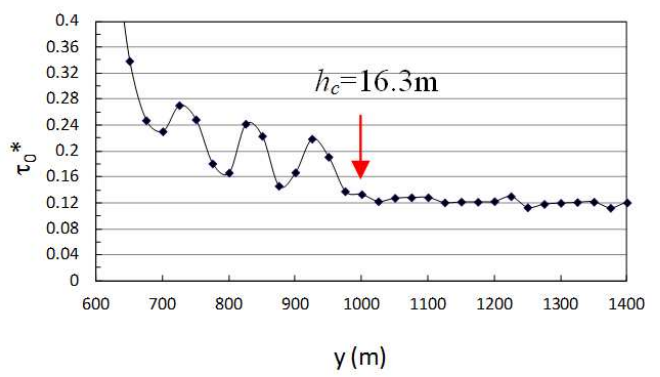

(d) $x=2100 \mathrm{~m}$

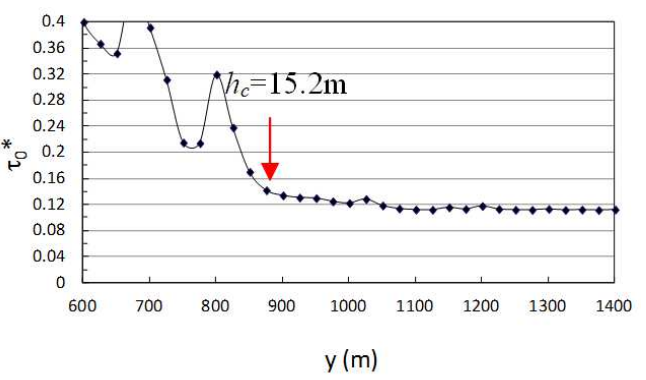

(f) $x=2650 \mathrm{~m}$

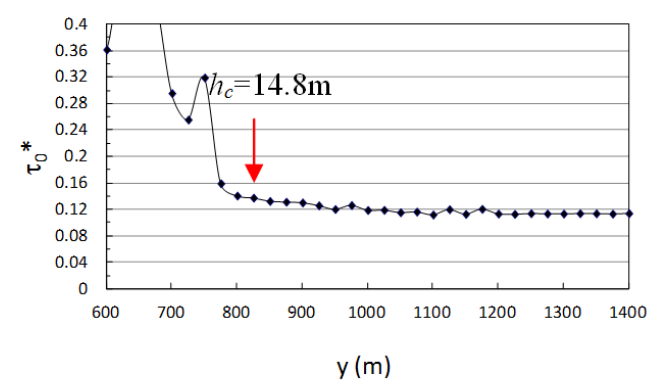

(g) $x=2950 \mathrm{~m}$

Figure 7. Cross sections on longshore direction of Shields parameter distribution, Sendai Port

\section{Yuriage Port}

Similar approach has been applied for Yuriage Port. The result is plotted as spatial map as shown in Fig. 8. The exaggeration of area up to $x=1200 \mathrm{~m}$ and $y=1000 \mathrm{~m}$ in longshore direction and cross-shore direction, respectively, is also shown. As the consequent of higher shear stress, higher $\tau_{0}^{*}$ is observed in the area near structure and also shallow region. Longshore variation of $h_{c}$ is overlaid on the spatial map of $\tau_{0^{*}}$ distribution. To observe more detail in term of hydrodynamic condition and its relation with $h_{c}$ 
variation, several cross sections are taken in longshore direction at the coast as seen in Fig. 9. It shows the consistency that for both study area $h_{c}$ is overlaid in $\tau_{0}^{*}=0.14$.

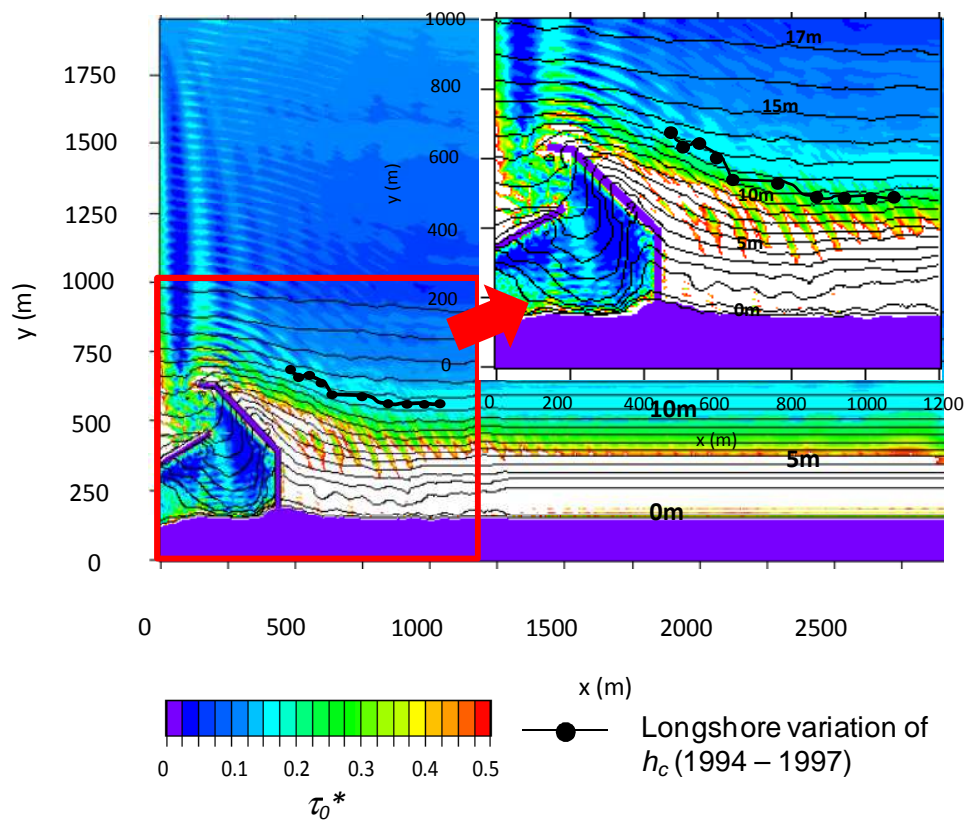

Figure 8. Shields parameter distribution, Yuriage Port

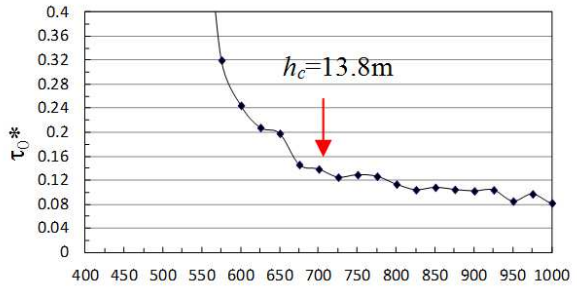

$\mathrm{y}(\mathrm{m})$

(a) $x=500 \mathrm{~m}$

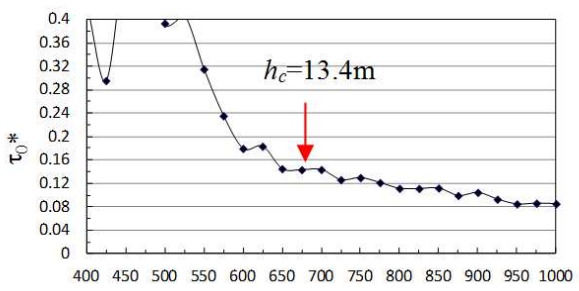

$\mathrm{y}(\mathrm{m})$

(c) $x=600 \mathrm{~m}$

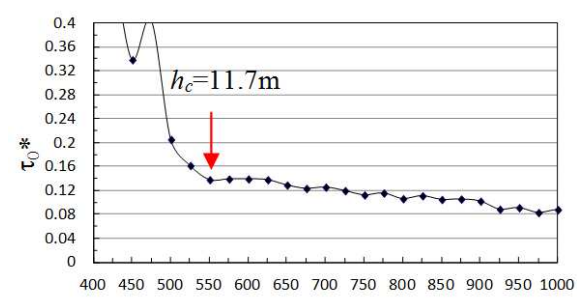

$y(m)$

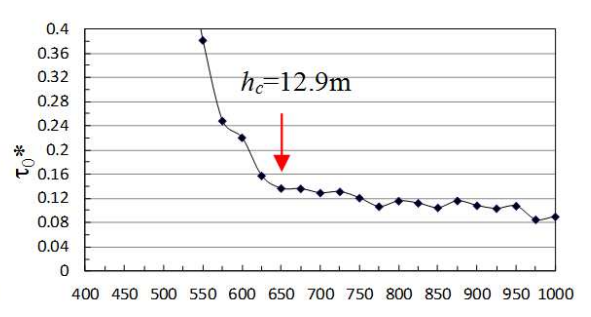

$y(m)$

(b) $x=550 \mathrm{~m}$

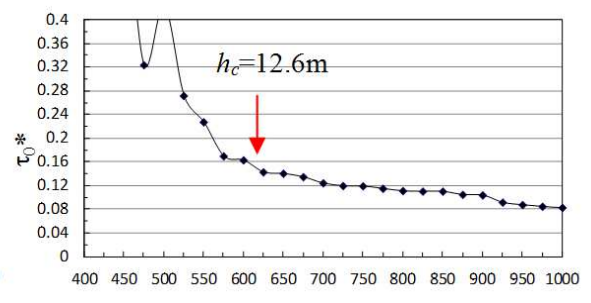

$y(m)$

(d) $x=675 \mathrm{~m}$

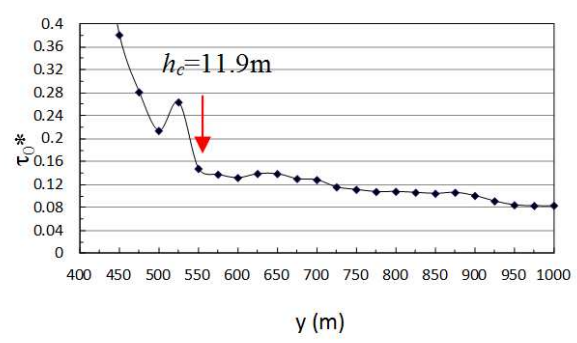

(f) $x=800 \mathrm{~m}$

(e) $x=700 \mathrm{~m}$

Figure 9. (see caption in the next page) 


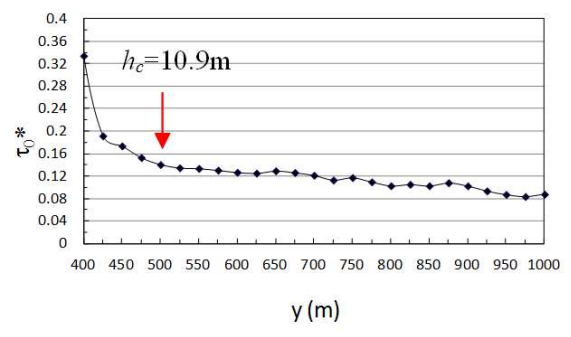

(g) $x=900 \mathrm{~m}$

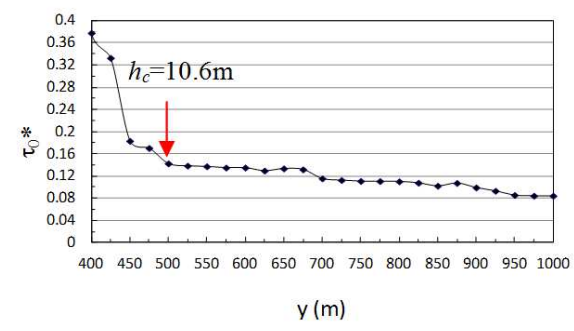

(i) $x=1075 \mathrm{~m}$

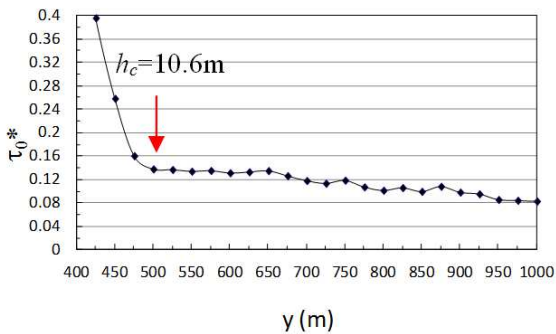

(h) $x=1000 \mathrm{~m}$

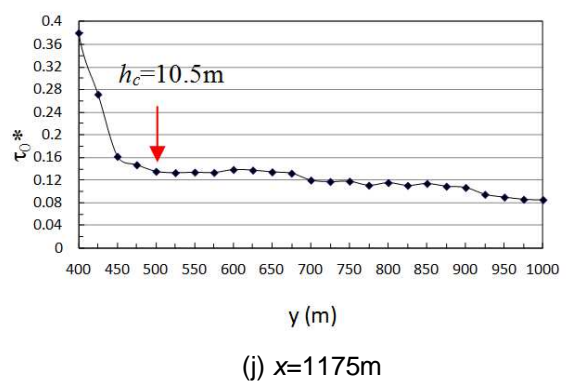

Figure 9. Cross sections on longshore direction of Shields parameter distribution, Yuriage Port

\section{CONCLUSION}

Determination of $h_{c}$ is proposed using bathymetry data for Sendai Port and Yuriage Port. The mean elevation and $\sigma$ are calculated based on bathymetry data series. Proposing longshore variation of $h_{c}$ has been done in same manner for each study areas. Several cross sections are taken along the coast. Time series bathymetry data are overlaid. The consistence value of $\sigma$ as $0.1 \mathrm{~m}$ is considered to predict $h_{c}$ in each cross section. The discrepancy observed in longshore variation of $h_{c}$ for Sendai Port and Yuriage Port indicate that coastal structures situated in that area give influence to $h_{c}$ variation. Considering the length and position of coastal structures, the discrepancy in Sendai Port is higher as compare with Yuriage Port.

Boussinesq model successfully simulates the hydrodynamic conditions expressed in term of $\tau_{0}^{*}$ in Sendai Port and Yuriage Port. The simulation on hydrodynamic condition shows that in the area near structure increasing wave action is identified by higher velocity distribution and higher shear stress. As the consequent, higher $\tau_{0} *$ is produced.

To investigate the effect of coastal structure to $h_{c}$ variation and hydrodynamic conditions in both study area, longshore variations of $h_{c}$ are overlaid on $\tau_{0} *$ spatial maps. It is obtained that the longshore variations of $h_{c}$ are laid in consistence value of $\tau_{0}{ }^{*}$. The longshore variation of $h_{c}$ is used to confirm the effect of coastal structure to hydrodynamic parameters. The discrepancy occurs in the area near structure is confirmed by higher value of $\tau_{0}^{*}$.

\section{ACKNOWLEDGMENTS}

The authors gratefully acknowledge to Grant-in-Aid for Scientific Research from Japan Society for Promotion of Science (No. 21360230). In additional, the authors also wish to express grateful thanks to Shiogama Port and Airport Office for providing aerial photographs and survey data of Sendai coast and to Sendai Office of River and National Highway, Ministry of Land Infrastructure and Transport for their kind offer of surveyed data for Yuriage Port. The first author is the scholar holder under Japanese Ministry of Education, Culture, Sports, Science and Technology.

\section{REFERENCES}

Abbott, M.B., A. Damsgaard, and G.S. Rodenhuis. 1973. System 21, "Jupiter" (a design system for two dimensional nearly horizontal flows), Journal of Hydraulic Research, 11(1), 1-28.

Abbott, M.B., A.D. McCowan, and I.R. Warren. 1984. Accuracy of short-wave numerical models, Journal of Hydraulic Engineering, 110(10), 1287-1301. 
Abbott, M.B., H.M. Petersen, and O. Skovgaard. 1978. On the numerical modelling of short waves in shallow water, Journal of Hydraulic Research, 16(3), 173-203.

Abbott, M.B. 1974. Continuous flows, discontinuous flows and numerical analysis, Journal of Hydraulic Research, 12(4), 417-467.

Beji, S., and J.A. Battjes. 1994. Numerical simulation of nonlinear wave propagation over a bar, Coastal Engineering, 23, 1-16.

Birkemeier, W. A. 1985. Field data on seaward limit of profile change., Journal of Waterway, Port, Coastal and Ocean Engineering, 111(3), 598-602.

Boussinesq, J. 1872. Thorie des ondes et des remous qui se propagent le long d'un canal rectangulaire horizontal, en communiquant au liquide contenu dans ce canal des vitesses sensiblement pareilles de la surface au fond, Journal de Mathmatique Pures et Appliques, 17, 55-108.

Capobianco, M., M. Larson, R.J. Nicholls, and N.C. 1997. Depth of closure: A contribution to the reconciliation of theory, practise and evidence, Proceedings of Coastal Dynamics'97, ASCE, 506515.

Dean, R.G., and R. Dalrymple. 2002. Coastal Processes: with engineering applications, Cambridge University Press, UK, 133-158 pp.

Francois, S., M.J.F. Stive, and F. Pons. 2004. Longshore variation of depth of closure on a micro-tidal wave-dominated coast, Proceedings of $29^{\text {th }}$ International Conference on Coastal Engineering, 3 , 2327-2339.

Gracia, V., J.A. Jimenez, and A. Sanchez-Arcilla. 1995. Nearshore profiles along the Ebro delta coast, implications for coastal processes, MEDCOAST 95, Tarragona, Spain, 1131-1143.

Gracia, V., J.A. Jimenez, A. Sanchez-Arcilla, J. Guillen, and A. Palaqes. 1998. Short-term relatively deep sedimentation on the Ebro delta coast. Opening the closure depth, Proceedings of $26^{\text {th }}$ International Coastal Engineering Conference, ASCE, 2902-2912.

Hallermeier, R.J. 1981. A profile zonation for seasonal sand beaches from wave climate, Coastal Engineering, 4, 253-277.

Hanson, H., and N.C. Kraus. 2011. Long-term evolution of a long-term evolution model, Journal of Coastal Research, 59, 118-129.

Hinton, C., and R.J. Nicholls. 1998. Spatial and temporal behaviour of depth of closure along the Holland coast, Proceedings of $26^{\text {th }}$ International Conference on Coastal Engineering, ASCE, 2913-2925.

Kabiling, M.B., and S. Sato. 1994. A numerical model for nonlinear waves and beach evolution including swash zone, Coastal Engineering in Japan, 37(1), 67-86.

Karambas, Th.V., and C. Koutitas. 1992. A breaking wave propagation model based on the Boussinesq equations, Coastal Engineering, 18, 1-19.

Kennedy, A.B., Q. Chen, J.T. Kirby, and R.A. Dalrymple. 2000. Boussinesq modeling of wave transformation, breaking, and runup. I:1D, Journal of Waterway, Port, Coastal, and Ocean Engineering, 126(1), 39-47.

Kraus, N.C., M. Larson, and R.A. Wise. 1999. Depths of closure in beach fill design, Proceedings of $12^{\text {th }}$ National Conference of Beach Preservation Technology, Shore and Beach Preservation Association, 271-286.

List, J.H., B.E. Jaffe, A.H. Sallenger, and M.E. Hansen. 1997. Bathymetric comparisons adjacent to the Louisiana barrier islands: processes of large scale change, Journal of Coastal Research, 13(3), 670-678.

Longuet-Higgins, M.S. 1970. Longshore currents generated by obliquely incident sea waves 1 and 2 , Journal of Geophysics Research, 75, 6778-6789 (Part 1), 6790-6801 (Part 2).

McCowan, A.D. 1987. The range of application of Boussinesq type numerical short wave models, Proceedings of $22^{\text {nd }}$ IAHR Congress, 378-384.

Nicholls, R. J., M. Larson, M. Capobianco, and W.A. Birkemeier. 1998a. Depth of Closure: Improving Understanding and Prediction, Proceedings of $26^{\text {th }}$ International Conference on Coastal Engineering, 2888-2901.

Nicholls, R.J., W.A. Birkemeier, and G. Le. 1998b. Evaluation of depth of closure using data from Duck, NC, USA, International Journal of Marine Geology, Geochemistry and Geophysics, 148, 179-201.

Nomura, K., T. Uda, A. Inaba, and T. Miyauchi. 1986. Deformation of sand spit at the mouth of Abukuma River, Proc. of Coastal Engineering, JSCE, 33, 267-271 (in Japanese). 
Nwogu, O. 1996. Numerical prediction of breaking waves and current with a Boussinesq model, Proceedings of $25^{\text {th }}$ International Conference on Coastal Engineering, 48074820 .

Peregrine, D.H. 1967. Long waves on a beach, Journal of Fluid Mechanics, 27(4), 815-827.

Pradjoko, E., H. Tanaka, and E. Henry. 2011. The effect of Sendai Port breakwater to sediment movement in its vicinity, Proceedings of $6^{\text {th }}$ International Conference on Coastal Structures $(C D$ $R O M)$.

Rózyński, G., Z. Pruszak, T. Okrój, and R.B. Zeidler. 1998. Depth of closure and seabed variability patterns, Proceedings of $26^{\text {th }}$ International Conference on Coastal Engineering, 2926-2939.

Sato, S., and N. Tanaka. 1962. Sand motion on the horizontal bottom under waves, Proceedings of $9^{\text {th }}$ Japanese Conference on Coastal Engineering, 95-100 (in Japanese).

Schäffer, H. A., P. Madsen, and R. Deigaard. 1993. A Boussinesq model for wave breaking in shallow water, Coastal Engineering, 20, 185-202.

Shibutani, Y., M. Kuroiwa, and Y. Matsubara. 2007. One-line model for predicting shoreline changes due to beach nourishments, Journal of Coastal Research, Special Issue, 50, 511-515.

Svendsen, I. A., K. Yu, and J. Veeramony. 1996. A boussinesq breaking wave model with vorticity, Proceedings of $25^{\text {th }}$ International Conference on Coastal Engineering, 1192-1204.

Tanaka, H., and A. Takahashi. 1995. Short-term shoreline change on Sendai Coast, Computer Modeling of Seas and Coastal Regions, 205-212.

Tanaka, H., and A. Thu. 1994. Full-range equation of friction coefficient and phase difference in a wave-current boundary layer, Coastal Engineering, 22, 237-254.

Uda, T. 1997. Beach erosion in Japan, Sankaido, 442 pp (in Japanese).

Wang, P., and R.A. Davis, Jr. 1999. Depth of closure and the equilibrium beach profile: a case study from Sand Key, west-central Florida, Shore and Beach, 67, 33-42.

Zacharioudaki, A., and D.E. Reeve. 2009. A note on the numerical solution of the one-line model, Environmental modelling and software, 25, 802-807.

Zelt, J. 1991. The runup of breaking and non-solitary waves, Coastal Engineering, 15, 205-246. 